\title{
CARACTERIZAÇÃO DAS PRINCIPAIS FEIÇÕES SUPERFICIAIS DE FUNDO E EM SUBSUPERFÍCIE NO LIMITE SUDOESTE DA BAÍA DE MACAPÁ, CANAL DO NORTE, RIO AMAZONAS
}

\author{
Marcos Vinícius da Silva BARROS ${ }^{1 *}$; Marcelo ROLLNIC²; Fábio Kiyoshi WATANABE² \\ 1Universidade Federal Fluminense. E-mail: marcosilva.oc@gmail.com. \\ *Autor correspondente \\ 2Universidade Federal do Pará. E-mail: rollnic@ufpa.br, fabiokwatanabe@gmail.com.
}

\begin{abstract}
RESUMO. A Baía de Macapá, por estar inserida a zona de médio estuário do Rio Amazonas, apresenta vestígios de alterações morfológicas diferenciadas pela forte dinâmica em um curto intervalo de tempo. 0 reflexo de tais alterações pode ser observado nas modificações morfoestruturais presentes no leito e subsuperfície. A análise dos perfis sísmicos em alta resolução pelo intervalo de frequência de $0,7 \mathrm{kHz}$ a $12,0 \mathrm{kHz}$ revela que as características apresentadas nas formas de fundo desencadeiam os processos modeladores do padrão de reflexão observados nos refletores em subsuperfície. Através desta relação foi possível identificar a predominância de cinco formas de fundo, quatro unidades estruturais e cinco sismofácies com o destaque para a identificação de uma feição de paleocanal. Observou-se que as variações morfológicas do leito são influenciadas pela constante atuação dos processos hidrodinâmicos e sedimentares ocorrentes periodicamente e vice-versa, corroborando para correlação entre as feições superficiais de fundo e as feições em subsuperfície.
\end{abstract}

Palavras-Chave: Morfologia, formas de fundo, sismofácies, paleocanal.

\begin{abstract}
The Macapá Bay, because it is inserted in the middle estuary zone of the Amazon River, presents evidences of different changes in a short time. The reflex of such changes can be observed in morphostructural modifications present in the bed and subsurfaces. The analysis of the high-resolution seismic profiles through on frequency range of $0.7 \mathrm{kHz}$ to $12.0 \mathrm{kHz}$ reveals that the features presented in the bedforms trigger the reflection pattern modelers processes observed in the subsurface reflectors. Through this relationship, it was possible to identify the predominance of five bedforms, four structural units and five seismic facies with highlight for the identification of a paleochannel feature. It was observed that the morphological variations of the bed are influenced by the constant actuation of the hydrodynamic processes and sedimentary that occur periodically and vice versa, corroborating to correlation between the superficial bottom features and the subsurface features.
\end{abstract}

Keywords: Morphology, bedforms, seismic facies, paleochannel. 
Barros et al. Caracterização das Principais Feições Superficiais de Fundo e em Subsuperfície no Limite Sudoste da Baía de Macapá, Canal do Norte, Rio Amazonas.

\section{INTRODUÇÃO}

O ambiente amazônico, em decorrência de sua elevada dinâmica, distingue-se dentre os demais por apresentar características singulares em relação ao desenvolvimento dos processos sedimentares, assim como a formação de estruturas morfológicas em diferentes escalas de tempo (Jaeger and Nittrouer, 1995). A evolução dos processos sedimentares atua neste ambiente na alteração da morfologia de leito e margem dos rios amazônicos, retrabalhando e transportando os sedimentos desde a cabeceira até a foz (Gallo and Vinzon, 2005; Guennec and Strasser, 2007). O Rio Amazonas, por se tratar de um rio de alta energia, exerce a importante tarefa de carreamento da carga de leito em direção a sua foz, contribuindo para o desenvolvimento das formas de fundo, distribuição e sumidouro de sedimentos (Wittmann et al., 2011). Estudos apontam a areia como sedimento predominante de fundo desde a região do alto estuário do Rio Amazonas até a sua foz na parte sul da plataforma continental (AmasSeds, 1990; Vital and Stattegger, 2000b). Contudo, depósitos de lama também foram registrados em várias zonas ao longo do mesmo, apresentando-se nas margens, planícies de maré e zonas de menor dinâmica (Dunne et al., 1998). Esse aspecto influencia na configuração das estruturas de fundo, setorizando a morfologia de acordo com as características in situ, como a aparição de barras arenosas de maré (tidal sand bars), ondas de areia (sand waves) e cristas arenosas (sand ridges), expostas durante a maré baixa (Santos et al., 2002). Além de pontais arenosos (spits) e deltas de marés (tidal delta) inseridos à linha de costa; e depósitos de dunas e planícies de cristas praias localizados no interior da planície costeira (Santos et al., 2005).

Grande parte dos processos dinâmicos responsáveis pelo retrabalhamento dos sedimentos é decorrente de sua inclusão no complexo estuarino amazônico, o qual se estende desde a plataforma continental até a montante próximo à cidade de Óbidos/PA (Gallo and Vinzon, 2005), apresentando dentre os demais processos: zonas de máxima turbidez com a contribuição para a formação de depósitos lamosos (Guennec and Strasser, 2007; Vilela, 2011); fluxos residuais convergentes decorrentes da assimetria da maré (Vinzon et al., 2005); floculação do material em suspensão, ocasionando a deposição de parte do material transportado pelas correntes (Geyer et al., 2004); circulação gravitacional, devido ao gradiente horizontal de densidade, e padrões estuarinos de circulação (Peakall et al., 2007). Vale ressaltar a importância da variação dos índices pluviométricos, sazonal com os efeitos da Zona de Convergência Intertropical (ZCIT) e interanual com a presença do fenômeno de El Niño de Oscilação Sul (ENOS), contribuindo para o aumento ou diminuição do nível das cotas do rio, o qual estabelece um regime de fluxo modificando a vazão na área (Molion, 1987; Santos et al., 2009; Wells, 1990). Tais variações são controladoras da dinâmica local, alterando periodicamente a vazão e conseguinte os valores das principais componentes de velocidade de fluxo local (Fernandes et al., 2007).

A quantidade de processos envolvidos aliados à complexidade do arranjo geomorfológico regional estabelecem a importância do conhecimento sobre a formação e desenvolvimento do sistema aluvial amazônico (Bourgoin et al., 2013). Os avanços metodológicos, em outras áreas 
Barros et al. Caracterização das Principais Feições Superficiais de Fundo e em Subsuperfície no Limite Sudoste da Baía de Macapá, Canal do Norte, Rio Amazonas.

do planeta, em geofísica de prospecção refletem a ampliação das pesquisas relacionadas a investigação das estruturas em sub superfície (Marroquín, 2014), microtopografia de leito (Neill et al., 2012), análise estrutural das fácies sísmicas ou sismofácies (Pigott et al., 2013), e reconstrução de ambientes pretéritos (Li et al., 2016). A aplicação dos métodos geofísicos para a investigação em subsuperfície tornou-se uma ferramenta importante para o avanço dos estudos voltados à morfodinâmica, auxiliando na compreensão dos processos sedimentares pertencentes a zona costeira (Miall, 2006). Na região, os estudos geomorfológicos direcionados aos processos morfodinâmicos são complementados pelos avanços das pesquisas relacionadas principalmente à configuração geomorfológica das estruturas sedimentares e a compreensão de formação das principais formas de fundo (Park and Latrubesse, 2014; Pinheiro and Vinzon, 2013). As estruturas sedimentares, no Rio Amazonas, variam espacialmente e em dimensão em um curto intervalo de tempo, devido a ação contínua de fortes correntes de maré de enchente e vazante (Fernandes et al., 2007). Essa característica é observada pela disposição das feições superficiais de fundo e abaixo do substrato (Damuth et al., 1983).

Observou-se uma similaridade entre essas duas áreas em relação as estruturas identificadas, levantando a hipótese que o ambiente na Baía de Macapá está sujeito a alterações graduais em algumas áreas e intempestiva em outras, apesar das diversidades nos processos de sedimentação e variabilidade das formas de leito apresentados na superfície do fundo e subsuperfície. Desta forma, esta pesquisa possui como objetivo identificar através de análise de perfis sísmicos de alta resolução, as alterações decorrentes da atividade contínua dos processos sedimentares ocorrentes no limite sudoeste da Baía de Macapá, área de inflexão do Canal do Norte, Rio Amazonas, relacionando as principais formas de fundo com o arranjo estrutural interno em subsuperfície (sismofácies). A compreensão dessas variações auxiliará na caracterização de desenvolvimento do ambiente, relacionando a ação dos processos atuantes com a estrutura sedimentar das fácies identificadas em subsuperfície.

\section{MATERIAL E MÉTODOS}

\section{ÁREA DE ESTUDO}

A área de estudo está localizada no limite sudoeste da Baía de Macapá com o levantamento realizado entre o distrito de Fazendinha/AP e a cidade de Macapá, cobrindo uma área de aproximadamente $18 \mathrm{~km} 2$ (Fig. 1). A morfologia de fundo mostra grandes modificações, principalmente se tratando das variações de profundidade, apresentando estruturas expostas na maré baixa como alguns bancos arenosos e profundidades alcançando cerca de 65 metros com a média de 30 metros. A Baía de Macapá é caracterizada como uma região de intensa dinâmica, pois além de estar incluída à zona de mistura em relação ao estuário do Rio Amazonas (Strasser et al., 2002; Vinzon et al., 2005), é localizada em uma área de inflexão do Canal do Norte que aliado a elevada carga sedimentar e descarga do rio, está sujeita a ação intensificada dos 
Barros et al. Caracterização das Principais Feições Superficiais de Fundo e em Subsuperfície no Limite Sudoste da Baía de Macapá, Canal do Norte, Rio Amazonas.

processos hidrodinâmicos, alterando a morfologia de leito e margem de algumas estruturas sedimentares de maneira acrecional ou erosiva em diferentes escalas temporais (Constantine et al., 2014; Martinez et al., 2009).

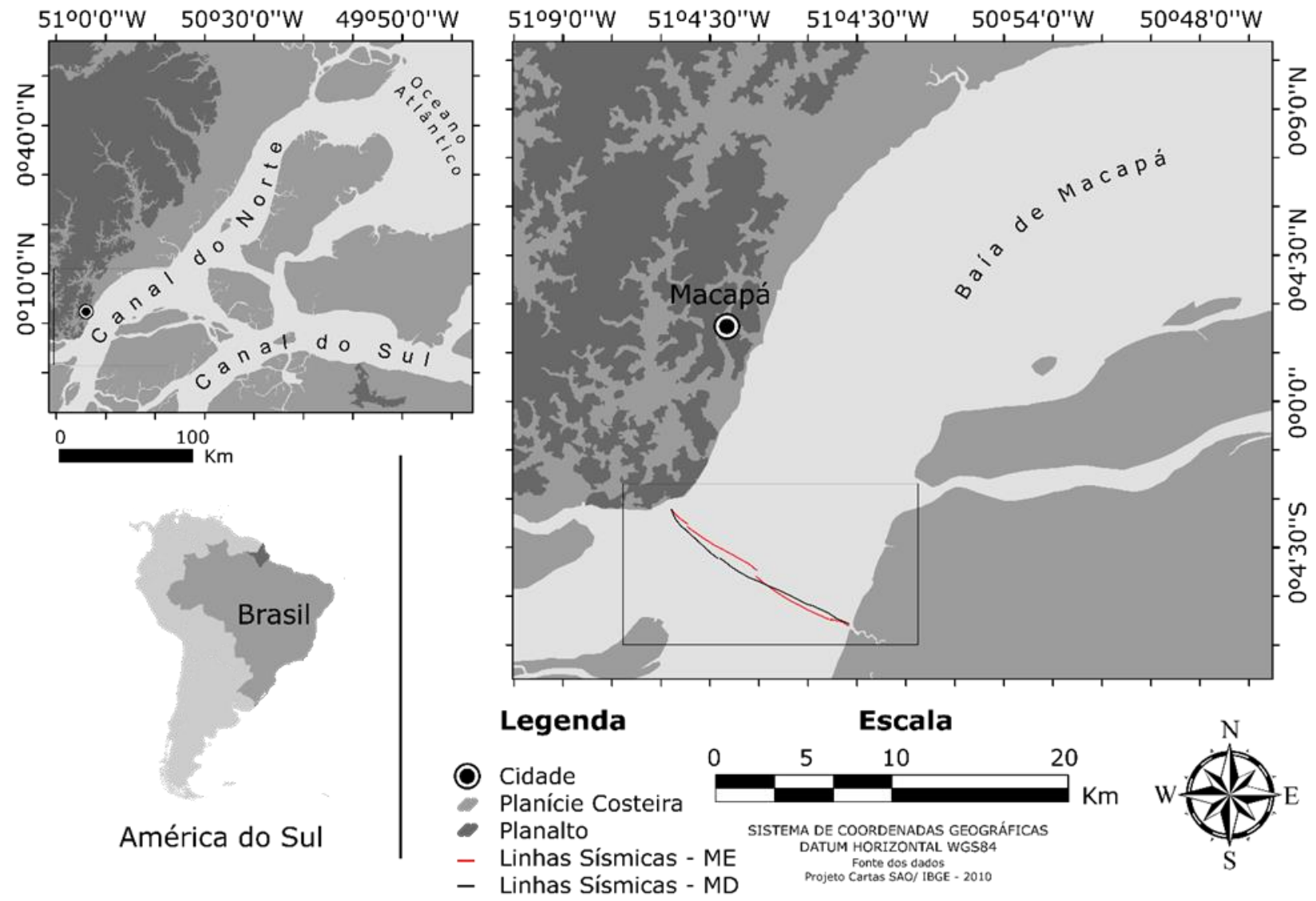

Figura 1. Mapa da área de estudo com ênfase nas linhas sísmicas iniciadas pela Margem Esquerda (ME) em vermelho e pelas linhas sísmicas iniciadas pela Margem Direita (MD) em preto.

Em relação as estruturas de fundo, algumas foram descritas por Vital et al. (1998) e Vital and Stattegger (2000a), a qual verificaram através de sonogramas de side scan sonar e perfis de eco sonda a presença de feições, como: Extensos campos de sand waves e canais de incisão em áreas distintas do Canal do Norte. Levando em consideração os aspectos das margens, a região em frente à cidade de Macapá é caracterizada pela baixa profundidade, sendo algo em torno de cinco metros em função da extrema acumulação sedimentar, alcançando larguras de até 500 metros, onde há o desenvolvimento de praias lamosas (Santos et al., 2009; Torres, 1997). Além disso, dados preliminares indicam que o canal principal próximo a margem de Macapá é preenchido com sedimentos de granulação fina nas bordas e sedimentos mais grosseiros em seu talvegue.

A área de levantamento dos perfis sísmicos foi idealizada na intenção de averiguar as maiores modificações morfológicas, por tratar-se de em uma zona de inflexão do Canal do Norte, onde há presença de ilhas, barras e pontais arenosos. Além de apresentar divergência aparente 
Barros et al. Caracterização das Principais Feições Superficiais de Fundo e em Subsuperfície no Limite Sudoste da Baía de Macapá, Canal do Norte, Rio Amazonas.

da direção de fluxo em alguns locais, decorrente da proximidade com as regiões mais rasas e, por conseguinte de menor dinâmica. Embora, o valor médio de vazão esteja estimado em períodos com baixo índice pluviométrico de 95500 m3.s-1 com predominância de fluxo em direção à jusante (Bourgoin et al., 2013; Guennec and Strasser, 2007).

\section{AQUISIÇÃO E PROCESSAMENTO DOS DADOS DE SÍSMICA RASA ESTRATÉGIA DE LEVANTAMENTO}

Para a caracterização das principais sismofácies foram utilizados seis perfis perpendiculares ao talvegue do Canal do Norte, sendo: Quatro iniciados pela margem esquerda (ME) do Rio Amazonas (Fazendinha/Macapá) denominados de " $\mathrm{A}$ " a " $\mathrm{D}$ " e dois iniciados pela margem direita (MD) (Ilha Queimada) chamados de " $E$ " e " $F$ ", sendo " $X$ " designado para o início e " $X$ "' para o fim do perfil (Fig. 2). As linhas de levantamento foram planejadas em carta batimétrica da área, digitalizada e georreferenciada (204 - Das Ilhas Pedreira a Ilha de Santana/AP) disponível pela Marinha do Brasil <http://www.mar.mil.br/dhn/chm/box-cartas-raster/raster_disponiveis.html>. Além disso, amostras de sedimento foram coletadas com a utilização de uma draga van Veen no início, meio e fim de cada linha sísmica apenas para reconhecimento e validação dos dados superficiais e por esse motivo não foi preciso plotagem de malha amostral.

O sistema de aquisição de alta resolução foi composto por um perfilador chirp de sub fundo SB 512i modulado para operar no intervalo de frequência de $7-12 \mathrm{kHz}$ acoplado a um DGPS Trimble para a navegação em software TrackMaker v.9.2. O levantamento ocorreu em maio de 2014, período em que ocorre as maiores modificações devido ao elevado regime pluviométrico e contou com auxílio de uma embarcação de pequeno porte, navegando a velocidade aproximada de 4 nós. Os dados sísmicos foram extraídos em formato original (*.jsf) pelo software Discovery, aproveitados em campanha de reconhecimento sísmico, amparada pelo projeto AMAZ em parceria com a University of Washington - USA.

\section{FLUXO DE PROCESSAMENTO}

Os registros foram processados e interpretados destacando as feições inseridas a superfície do fundo e em sub superfície, com foco na identificação das principais formas de fundo e arranjo estrutural dos refletores sísmicos para a caracterização das sismofácies. Para isso, definiram-se primeiramente as unidades estruturais predominantes em cada perfil, através de sua composição sedimentar superficial e configuração das feições observadas em sub superfície. Em seguida, analisou-se o arranjo dos refletores inseridos às unidades através do processamento em software Reflex Win v.6.1.

Através dos testes de parametrização optou-se por aplicar o fluxo de processamento seguindo a seguinte ordem: 1) Leitura do perfil sísmico com a importação do bruto; 2) Análise Geométrica com a definição da extensão real do perfil, remoção do ganho de aquisição inicial e 
corte manual do tempo duplo; 3) Análise Espectral com a amplificação do sinal sísmico pela utilização da primeira derivada e exportação do espectro de frequência para a extração das janelas espectrais; 4) Filtro unidimensional de deconvolução preditiva para a suavização de sinais duplos (suavização de múltipla) e bidimensional em " $\mathrm{X}$ e $Y$ " para remoção dos ruídos de interferência mínima; 5) Aplicação do ganho de compensação da divergência geométrica, evidenciando os refletores em profundidade; e 6) Realce dos principais refletores pelo método de envelopamento.

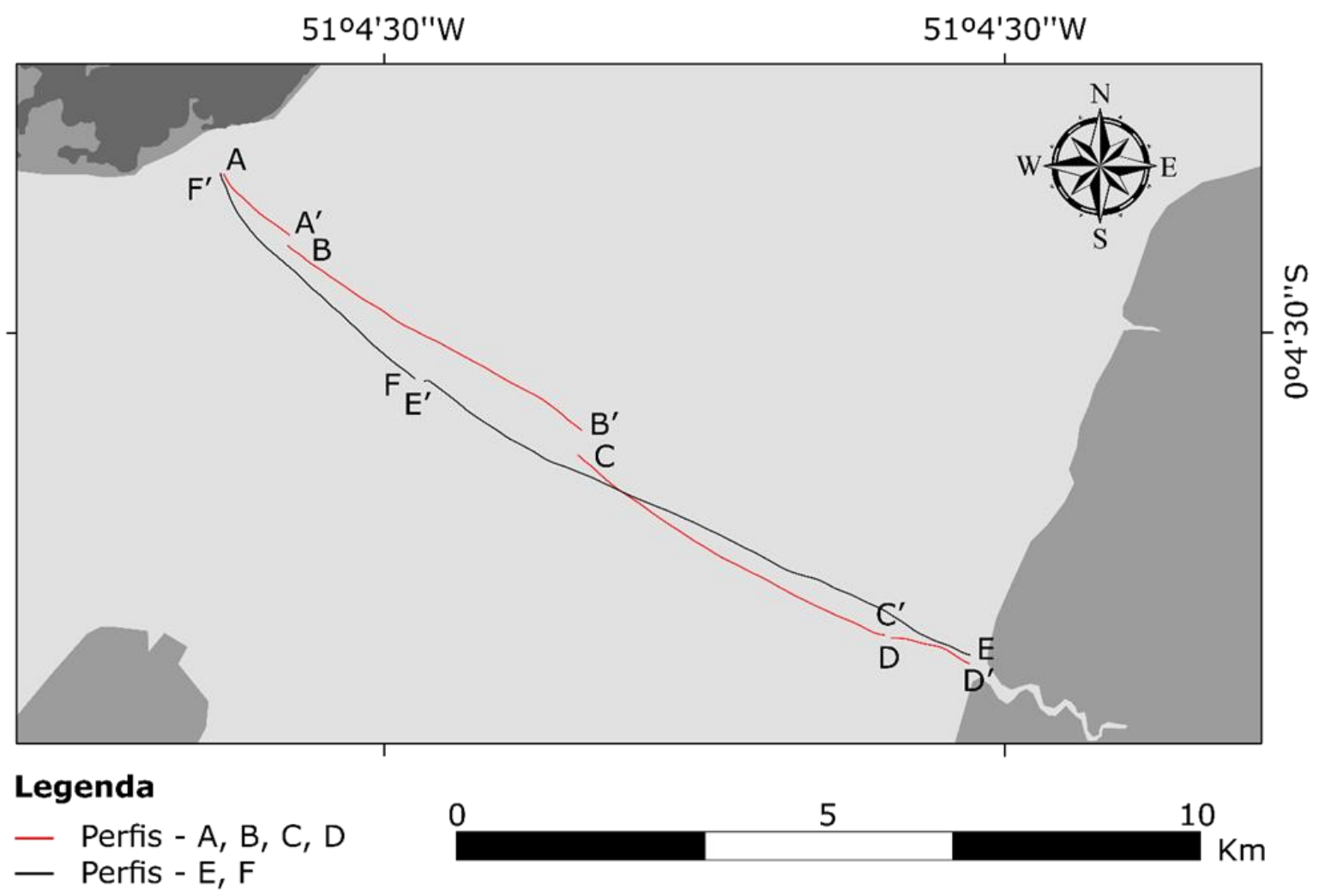

Figura 2. Configuração espacial e limites dos perfis sísmicos iniciados pela margem esquerda ( $A, B, C$ e $D)$ em vermelho e com início pela margem direita (E e F) em preto.

\section{RESULTADOS}

\section{GEOMORFOLOGIA DAS PRINCIPAIS ESTRUTURAS DE FUNDO}

A Baía de Macapá apresenta várias feições de fundo, distribuídas das margens ao centro. Entre as feições, identificaram-se cinco formas de leito com maior domínio espacial dentre as demais, caracterizadas de acordo com a composição sedimentológica, profundidade de formação e dinâmica de fluxo, sendo: i) Megaripples; ii) Sand Waves; iii) Tidal Sand Bars; iv) Canais Incisos; e v) Canal Principal (Fig. 2). Todas as cinco formas de leito apresentam características próprias de acordo com as especificações dinâmicas e sedimentares da área, como descritas a seguir. 
Barros et al. Caracterização das Principais Feições Superficiais de Fundo e em Subsuperfície no Limite Sudoste da Baía de Macapá, Canal do Norte, Rio Amazonas.

\section{i) Megaripples}

As formas do tipo megaripples estendem-se por praticamente toda a área de estudo, estando concentradas principalmente às profundidades de até 15 metros. Contudo, também podem se formar em profundidades maiores dependendo da disponibilidade de sedimentos e dinâmica de fluxo. Estas formas também podem estar presentes cavalgantes sobre formas de escalas maiores como sand waves e tidal sand bars. As megaripples apresentam dimensões simétricas de fácies triangulares, desenvolvendo-se predominantemente em escala centimétrica. O tipo de sedimento encontrado para essas feições é predominantemente arenoso de granulação fina a muito fina, comumente concentrado em regiões mais rasas e com moderada energia de velocidade de fluxo.

\section{ii) Sand Waves}

As formas do tipo sand waves foram identificadas nas bordas do canal principal e sobre as tidal sand bars, observadas em profundidades em cerca de 20 metros e zonas mais rasas. As sand waves estão dispostas obliquamente a direção do canal principal e geralmente apresentam morfologia assimétrica com uma das fácies mais inclinadas em relação a outra, alcançando altura aproximada de dois metros, largura em cerca de quatro metros e comprimento longitudinal na escala de quilômetros. Os sedimentos predominantes identificados nesta forma de fundo são compostos principalmente de material arenoso de granulação média, fina e muito fina, embora haja a presença de finas lentes de lama inseridas em suas calhas.

\section{iii) Tidal Sand Bars}

Essas formas estão localizadas predominantemente na zona central da Baía de Macapá, dispostas longitudinalmente em relação ao talvegue do Canal do Norte, ou inseridas em ambientes de menor dinâmica em áreas adjacentes as ilhas. As tidal sand bars possuem dimensões em escala de quilômetros, podendo variar, assim como as demais formas de fundo, de acordo com a profundidade, hidrodinâmica e disponibilidade de sedimento. Como o próprio nome ressalta, sua constituição sedimentológica é principalmente de areia, variando a granulometria em média, fina e muito fina. Essa composição somente é alterada em pequenas porções de suas bordas ou em zonas mais abrigadas, onde nota-se o predomínio de material lamosos.

\section{iv) Canais Incisos}

A forma do tipo canal inciso foi identificada às margens e talvegue dos canais principais e em áreas isoladas na base das formas de tidal sand bars. Por esse motivo, a profundidade de formação não pode ser considerada parâmetro de avaliação para a caracterização dessas formas de fundo. Na Baía de Macapá, os canais incisos apresentam dimensões variáveis, inseridos as escalas de metros se tratando da altura ou profundidade e de quilômetros em relação a largura 
Barros et al. Caracterização das Principais Feições Superficiais de Fundo e em Subsuperfície no Limite Sudoste da Baía de Macapá, Canal do Norte, Rio Amazonas.

e ao comprimento longitudinal. Os sedimentos identificados também variam de acordo com a sua localização, podendo ser predominantemente arenosos de granulação média a fina no talvegue e lamosos nas áreas adjacentes as bordas dos canais principais.

\section{v) Canal Principal}

O Canal Principal pode ser identificado em três áreas da Baía de Macapá, estando presente próximo a margem de Fazendinha/Macapá, a margem da Ilha Queimada e na parte central do Canal do Norte. Os três canais identificados possuem profundidade média de 30 metros com algumas variações na morfologia do leito, a qual pode apresentar elevada declividade nas bordas e leito irregular (forma em "V") ou baixa inclinação com leito regular (forma em "U"). Os sedimentos predominantes são de granulação fina com concentração de areia na parte inferior das bordas e talvegue e lama na parte superior da borda e em alguns terraços.

\section{CARACTERIZAÇÃO DAS UNIDADES ESTRUTURAIS E IDENTIFICAÇÃO DAS SISMOFÁCIES}

Na Baía de Macapá foram identificadas quatro unidades estruturais: Unidade I; Unidade II; Unidade III; e Unidade IV. Todas as unidades possuem propriedades particulares em relação principalmente das características intrínsecas relacionadas as formas de fundo. Além disso, os processos de sedimentação diferenciados favorecem a heterogeneidade dos arranjos e padrões de reflexão em subsuperfície. Observou-se que cada unidade estrutural comporta pelo menos um tipo de sismofácies típicas de ambientes fluviais de elevada energia, classificadas como fácies de estratos ou do tipo " $\mathrm{S}$ ". Desta maneira, foram identificadas cinco sismofácies no total: Tipo SP1; Tipo SP2; Tipo SC; Tipo SS; e Tipo SCAN. As cinco sismofácies são caracterizadas com padrões de estratificação, as quais apresentam feições distintas de formação e desenvolvimento estrutural de elementos internos e externos. Tais elementos relacionam-se com as unidades estruturais e, por conseguinte com as formas de fundo (Fig. 3).

\section{Unidade I - Ripples Cavalgantes}

A Unidade $I$ está associada as formas de megaripples, as quais encontram-se na maioria das vezes cavalgantes sobre outras formas de fundo de escala superior. Esta unidade normalmente está acomodada sobre um refletor contínuo e retilíneo caracterizado como uma superfície de erosão (Superfície 1) a aproximadamente seis metros de profundidade e refletores ondulados em áreas mais afastadas, inseridos a profundidade aproximada de dois metros abaixo do substrato. O arranjo dos refletores é caracterizado com amplitudes altas e baixas, além da configuração paralela e subparalela com pouca continuidade lateral. Isto é corroborado pela perda do sinal sísmico em algumas áreas, favorecendo a atenuação dos refletores principais, enquanto que, em algumas áreas o sinal demonstrou elevada penetração com resposta imediata de sua amplitude (Fig. 4). 
Barros et al. Caracterização das Principais Feições Superficiais de Fundo e em Subsuperfície no Limite Sudoste da Baía de Macapá, Canal do Norte, Rio Amazonas.

O refletor de alta amplitude inserido em áreas isoladas pode ser considerado o embasamento acústico. Essas características representam a sismofácies do tipo SP2, onde observa-se refletores com arranjo interno predominantemente subparalelos e deficiência na identificação de continuidade lateral.

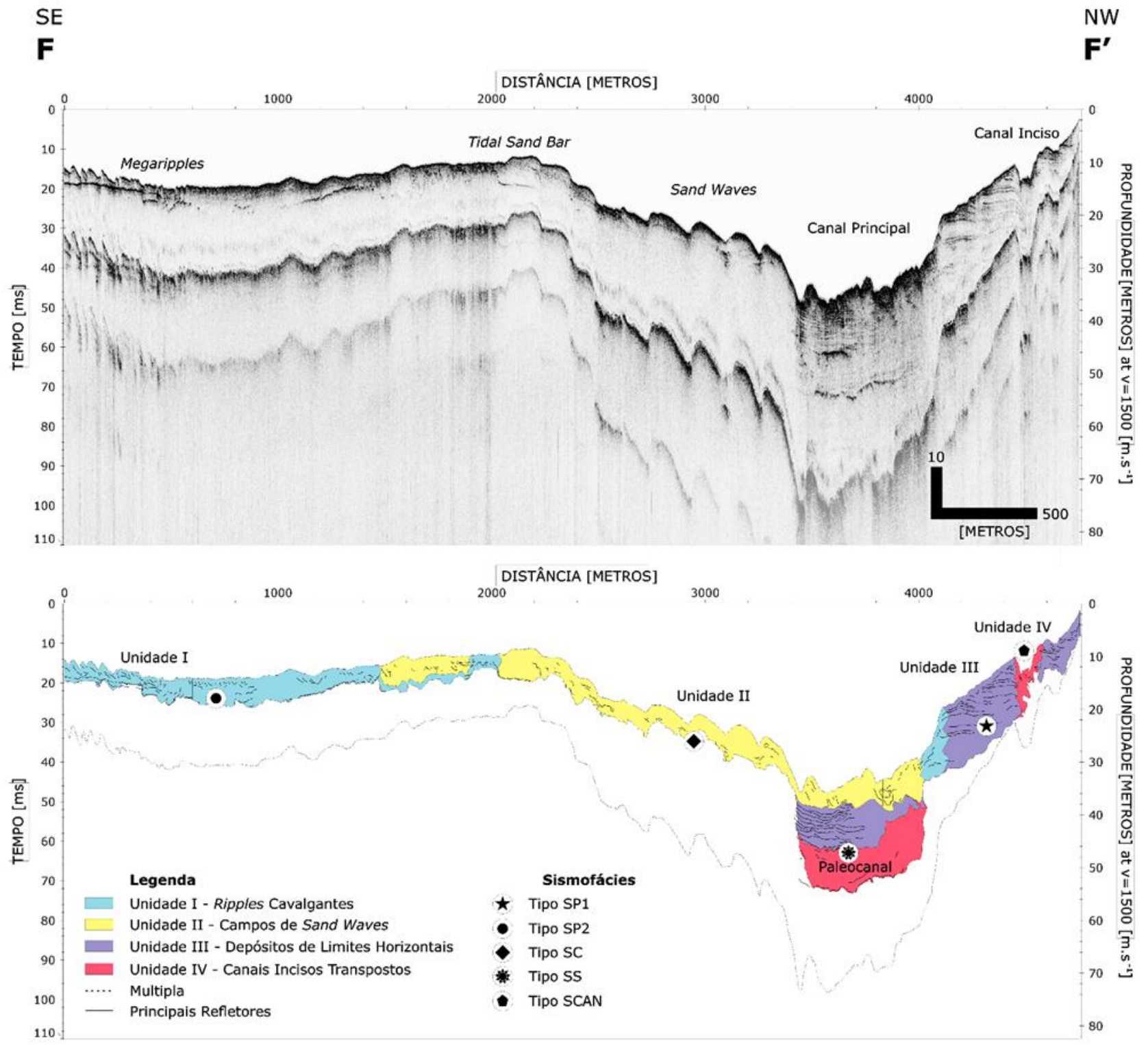

Figura 3. Caracterização morfoestrutural do perfil sísmico " $F "$, correlacionando as principais formas de fundo, unidades estruturais e sismofácies com o destaque para a feição de paleocanal identificada na Unit ICT a profundidade aproximada de 50 metros. 


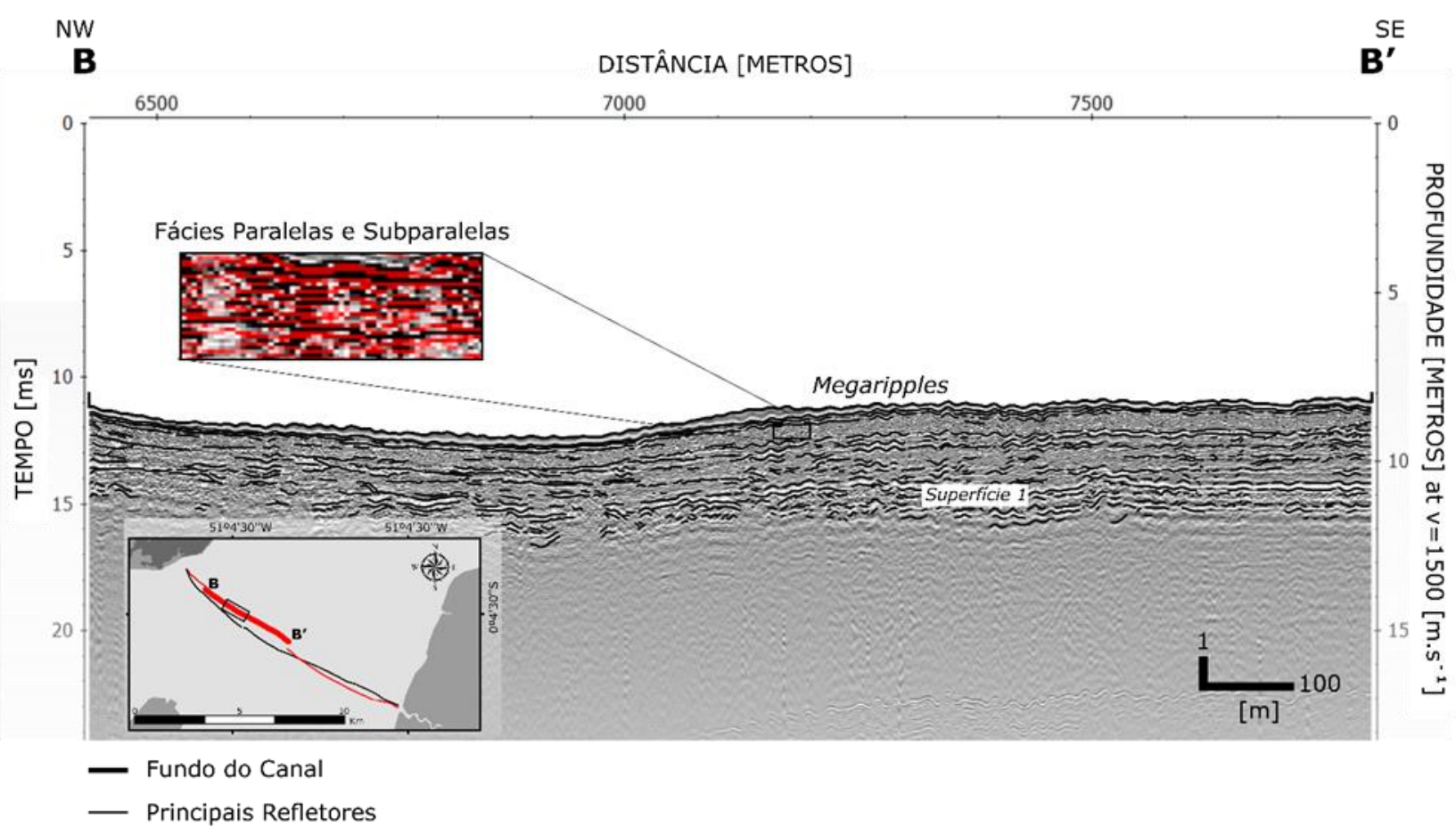

Figura 4. Associação da forma de fundo megaripples com a presença do arranjo de fácies paralelos e subparalelos, classificado segundo Mitchum et al. (1977) e Ribeiro (2001) como sismofácies tipo SP2.

\section{Unidade II - Campos de Sand Waves}

As sand waves são as formas de fundo relacionadas a Unidade II. A presença das sand waves indicam maiores velocidades de corrente para a manutenção e formação dessas estruturas. Outra característica desta unidade é a baixa capacidade de penetração do sinal sísmico, sendo limitada principalmente devido ao tipo de sedimento em sua composição, o qual é predominantemente arenoso e/ou grau de compactação. O arranjo dos refletores nesta unidade condiciona a sismofácies do tipo SC, onde nota-se a ausência de padrão regular em sua disposição acompanhado de fácies translucidas e disformes (Fig. 5).

Apesar da baixa capacidade de penetração do sinal sísmico na Unidade $I I$, observa-se um padrão na disposição dos refletores em profundidade, apresentando ligeira inclinação em direção a face mais íngreme, enquanto que a maioria se apresenta caoticamente na maior parte da seção.

\section{Unidade III - Depósitos de Limites Horizontais}

A Unidade III foi identificada em áreas do meio do Canal do Norte adjacentes a pequenas ilhas e próxima as margens, porém excepcionalmente também pôde ser identificada dentro dos canais principais. Nesta unidade se verificou uma sequência de refletores de alta amplitude plano paralelos, sobrepostos localizados em áreas isoladas próximas a base das formas do tipo tidal sand bars e nas margens do Canal do Norte. Esta unidade apresenta uma espessa camada de sedimentos de configuração estratificada alcançando cerca de 15 metros de profundidade com variações em algumas áreas localizadas nas margens e próximas as zonas mais rasas. A 
disposição paralela dos refletores com a identificação nítida de continuidade lateral podem ser consideradas as principais características para a classificação da sismofácies do tipo SP1 (Fig. 6), tipicamente reconhecidas em depósitos de bancos de areia.

Além da configuração plano paralela, esta unidade também pode ser caracterizada pela presença de refletores de elevada continuidade lateral com ligeira inclinação e configuração de fácies desconformes com indicação de superfície erosiva e deposição irregular, normalmente verificada em depósitos fluviais de baixa ou extrema energia dinâmica.

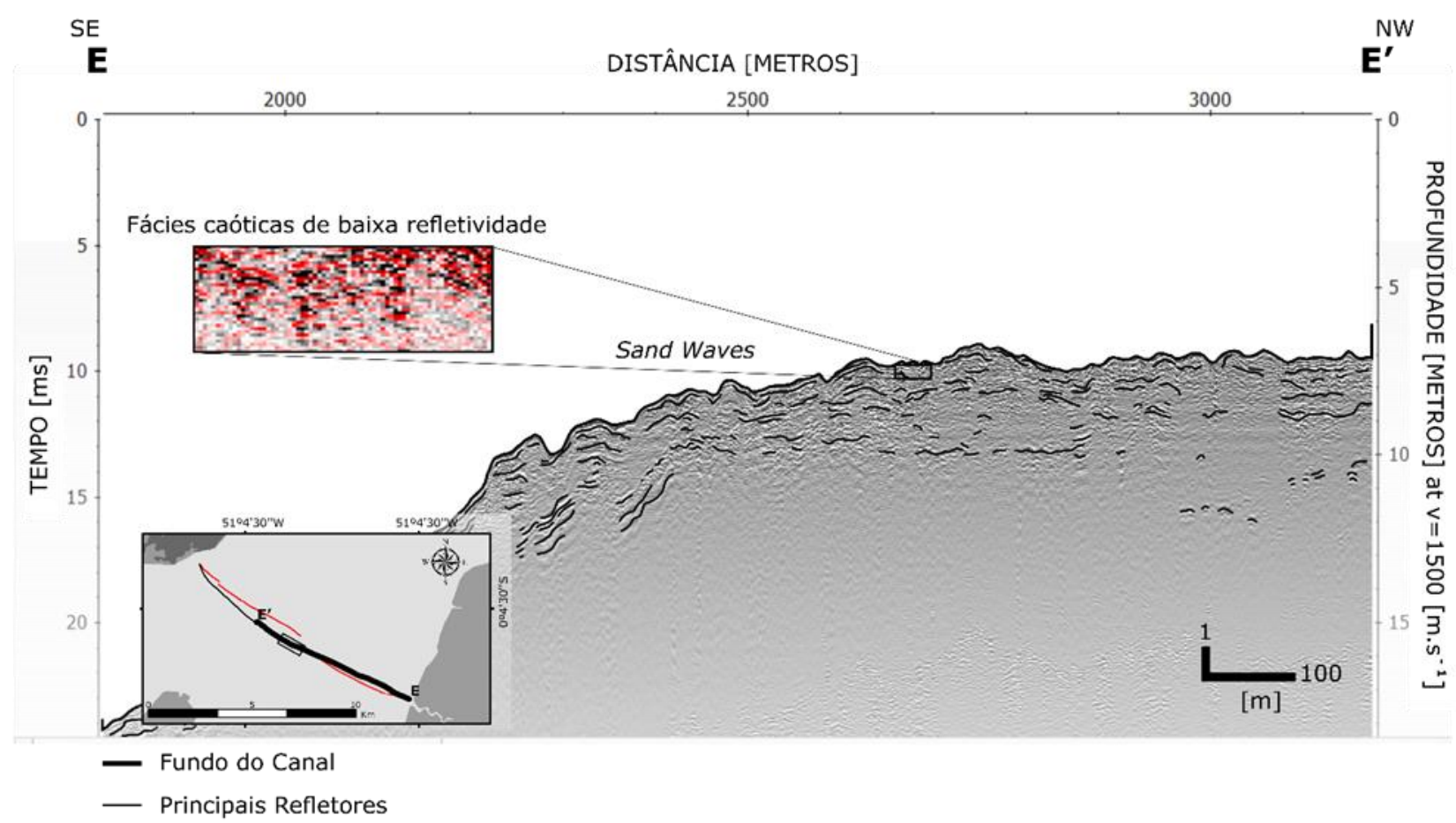

Figura 5. Associação da forma de fundo sand waves com arranjo de fácies caótico e de baixa refletividade, classificado segundo Mitchum et al. (1977) e Ribeiro (2001) como sismofácies tipo SC.

\section{Unidade IV - Canais Incisos Transpostos}

A Unidade IV é caracterizada pela presença de duas superfícies de erosão (Superfície 2 e Superfície 3), culminando na presença de dois refletores de alta amplitude inseridos nas profundidades de 55 e 65 metros respectivamente. A primeira superfície apresenta disposição côncava e é acompanhada de uma série de refletores horizontais sotopostos em configuração plano paralela, inclinados e/ou mergulhantes e a base marcada com a presença de alguns canais incisos. Essa feição pôde ser observada no talvegue do canal principal com dimensões em cerca de 10 metros de profundidade e largura e prolongamento em escala quilométrica.

A Superfície 3 demonstra similaridades com a Superfície 2 em relação a alguns refletores de configuração inclinada e/ou mergulhante, além da presença de canais incisos em sua base. Contudo, a Superfície 3 é marcada pela transparência acústica e a total ausência dos refletores sobrepostos de disposição horizontal. 


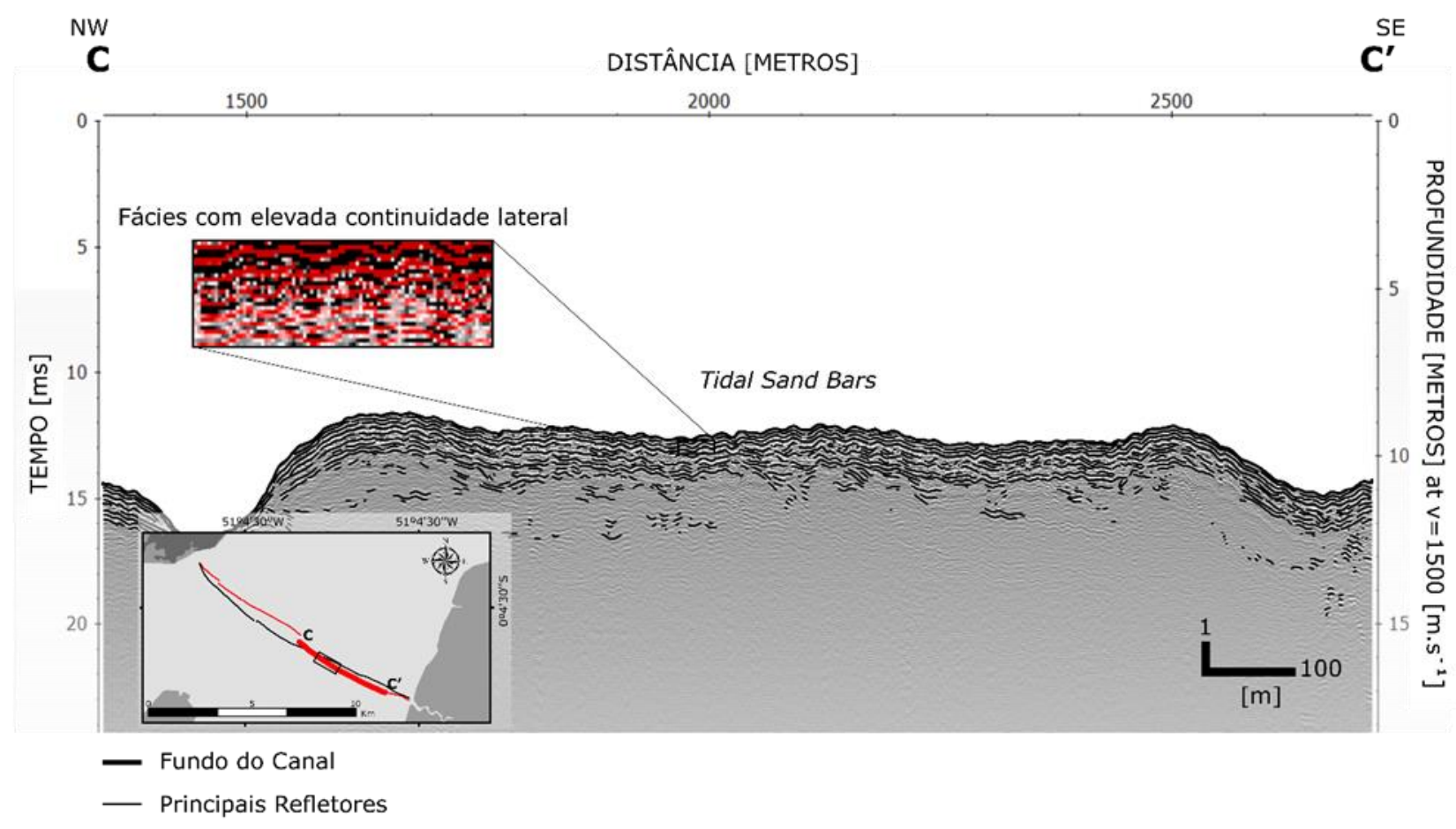

Figura 6. Associação da forma de fundo tidal sand bars com arranjo de fácies com alta continuidade lateral e elevada refletividade, classificado segundo Mitchum et al. (1977) e Ribeiro (2001) como sismofácies tipo SP1.

Na Unidade IV consegue-se distinguir sismofácies do tipo SS associadas principalmente a Superfície 2 e SCAN associadas a Superfície 3, caracterizados respectivamente pela distribuição sigmoide no arranjo dos refletores com a presença de terminações superiores e inferiores tangenciais em relação ao refletor com indicação de paleocanal, assim como pela configuração côncava seguida de padrões subparalelos inclinados em direção a calha (Fig. 7).

Em análise das sismofácies em subsuperfície, assim como a Unidade III, também se observou refletores inclinados, côncavos e mergulhantes apresentando desconformidade, identificação de superfície erosiva e deposição irregular. Contudo, possui arranjo de fácies progradantes com a indicação de canais de incisão medindo em média aproximadamente quatro metros de profundidade, 200 metros de largura e prolongamento na escala de quilômetros. 


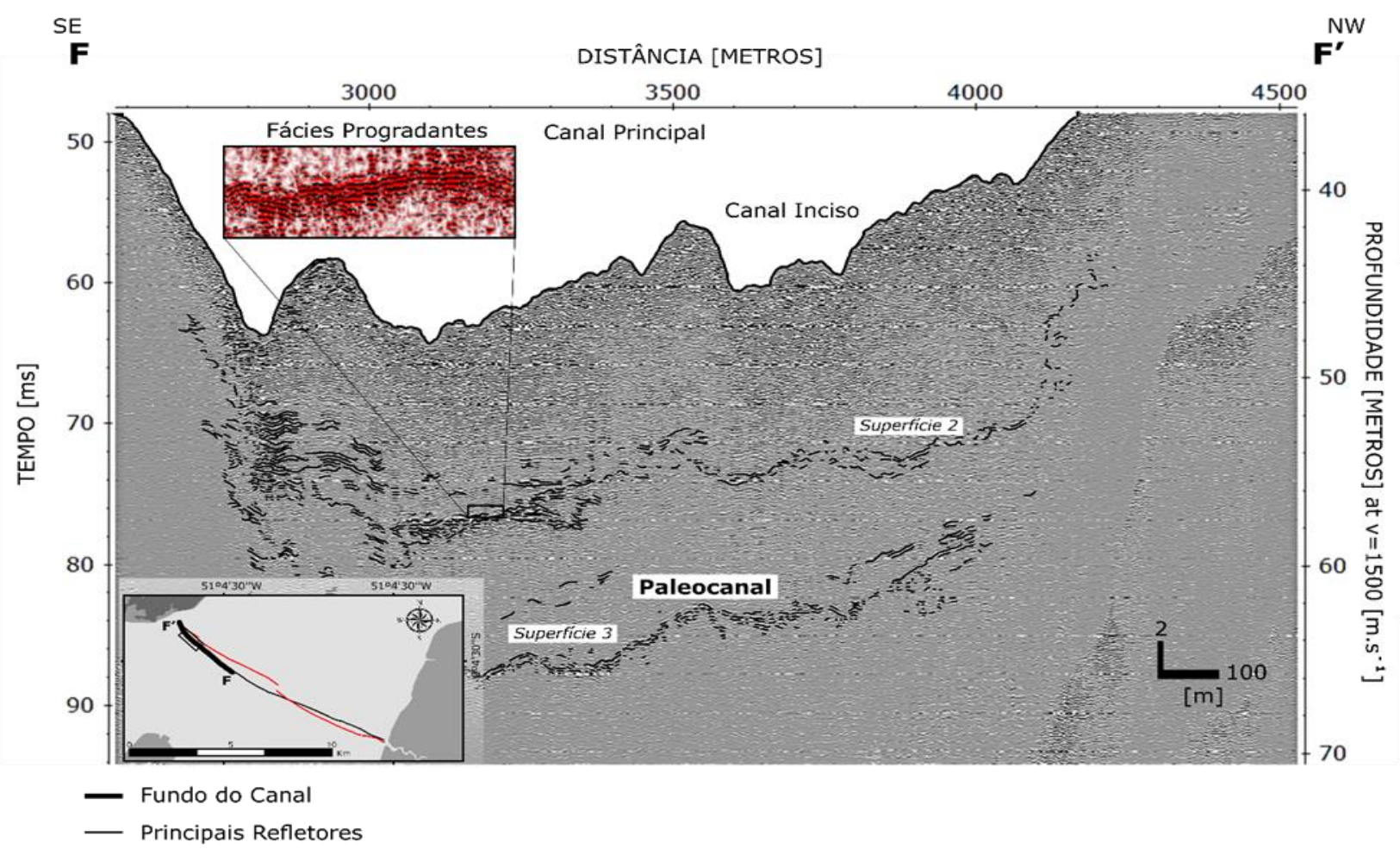

Figura 7. Associação da forma de fundo canal principal e canais incisos com arranjo de fácies progradantes de distribuição sigmoide e terminações tangenciais de elevada refletividade e arranjo côncavo de padrões subparalelos, classificados respectivamente segundo Mitchum et al. (1977) e Ribeiro (2001) como sismofácies tipo SS e SCAN.

\section{DISCUSSÃo}

A relação entre as formas de leito com as sismofácies identificadas, sugeriu que os processos hidrodinâmicos em ambientes fluviais trabalham em conjunto com a disponibilidade de sedimentos, originando a formação e desenvolvimento de diversas feições, formas e estruturas de fundo e em subsuperfície (Cartigny et al., 2011; Dalrymple et al., 1992; Packman et al., 2004). Na Baía de Macapá, a resposta sedimentar em superfície pode ser associada às formas de leito, enquanto que, em subsuperfície destacam-se a presença de sismofácies com características distintas em relação ao desenvolvimento das estruturas (Jaeger and Nittrouer, 1995; Li et al., 2016). Além disso, esta diversidade também está associada à alteração no padrão de sedimentação provocado pela: hidrodinâmica com a alteração dos valores de correntes e circulação estuarina; variação granulométrica; e espacialização das estruturas, as quais podem estar sujeitas a maiores intensidades de correntes como áreas próximas aos canais ou menores intensidades como margens e áreas adjacentes às ilhas ou bancos expostos em maré baixa (Fernandes et al., 2007; Strasser, 2002). A descrição da relação entre as feições identificadas na superfície do fundo e em subsuperfície pode ser observada resumidamente na Tabela 1. 
Barros et al. Caracterização das Principais Feições Superficiais de Fundo e em Subsuperfície no Limite Sudoste da Baía de Macapá, Canal do Norte, Rio Amazonas.

Tabela 1. Descrição da relação entre as feições superficiais de fundo e as feições identificadas em subsuperfície.

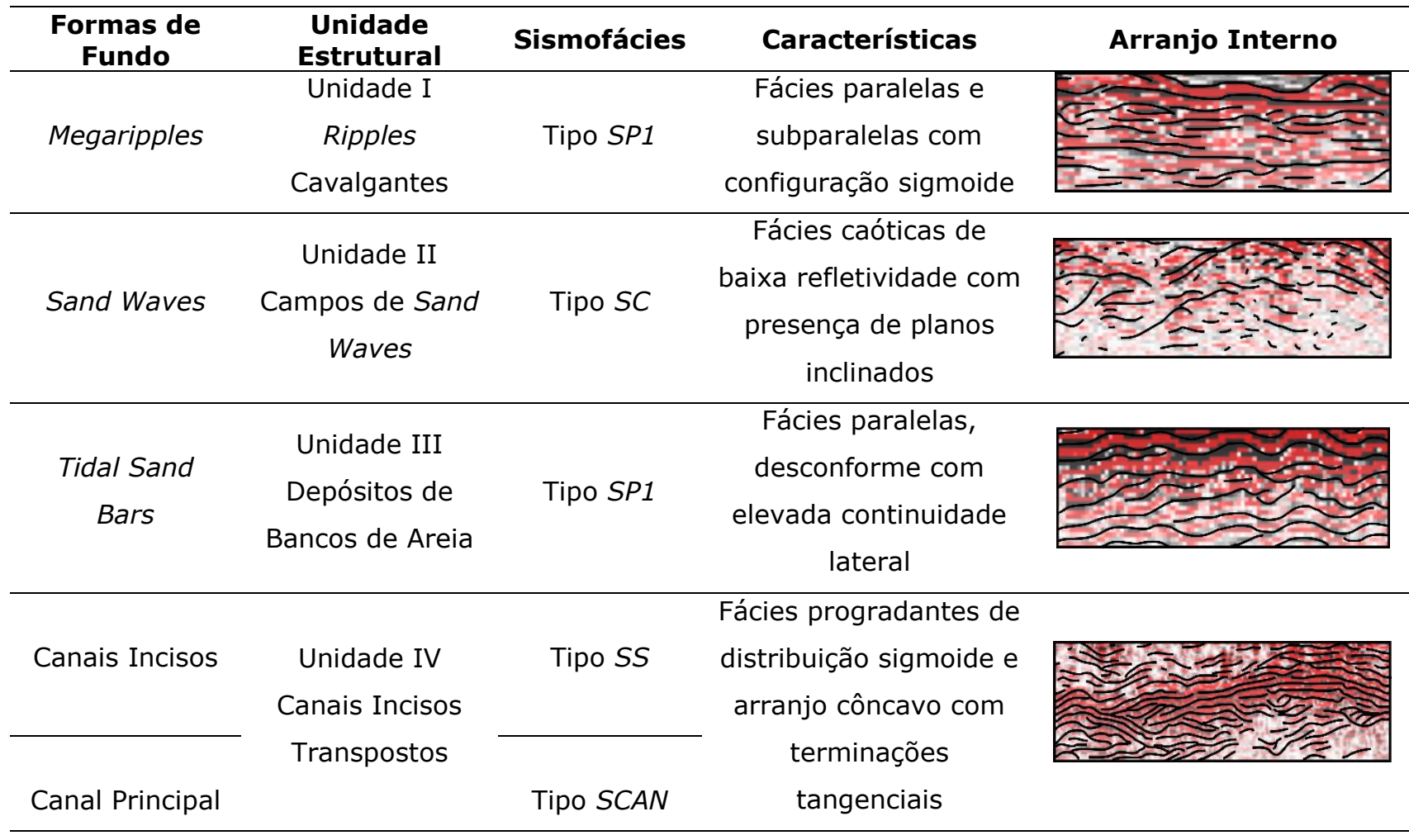

O processo de sedimentação em ambientes fluviais está ligado diretamente às condições locais, variando de acordo com a complexidade hidrodinâmica (Gomez-Velez et al., 2015). A complexidade dos processos envolvidos na dinâmica de escoamentos determina o comportamento físico de cada ambiente, fornecendo peculiaridades, as quais estão associadas geralmente às variáveis envolvidas e sua magnitude, gerando modificações nas características inerentes a esses processos (Bourgoin et al., 2013; Packman et al., 2004). O transporte de sedimento em ambientes fluviais normalmente é heterogêneo devido à complexidade dos fatores controladores do sistema hidrodinâmico, os quais apresentam particularidades tratando-se principalmente dos aspectos físicos e geológicos (Miall, 2002; Neill et al., 2012).

A Baía de Macapá apresenta variação lateral e vertical em relação às feições identificadas, onde tais feições estão condicionadas as características hidrodinâmicas e sedimentológicas in situ (Strasser et al., 2002). As particularidades apresentadas do arcabouço sedimentológico originam as características para a classificação das quatro unidades estruturais, distribuídas de uma margem a outra do Canal do Norte. Entretanto, apesar das diversidades nos processos de sedimentação na superfície do fundo e em subsuperfície, verificou-se que ambas estão relacionadas de acordo com a disposição das formas de fundo e pelo arranjo dos refletores corroborados pelas sismofácies, já que os parâmetros de melhor definição para sismofácies são a configuração de reflexões internas, geometria externa (forma 3D), formas de preenchimento, assim como parâmetros relacionados ao padrão de reflexões como amplitude e continuidade (Du et al., 2015; Mitchum Jr et al., 1977). 
Barros et al. Caracterização das Principais Feições Superficiais de Fundo e em Subsuperfície no Limite Sudoste da Baía de Macapá, Canal do Norte, Rio Amazonas.

A relação das unidades estruturais com a presença das sismofácies está atrelada principalmente a configuração interna ou arranjo dos refletores (Gomes et al., 2014; Vital et al., 2010). A análise espacial dos refletores sísmicos revelou pelo menos cinco sismofácies, com o indicativo de associação as alterações morfológicas de leito. As informações obtidas no processamento também corroboram a correlação entre as unidades estruturais e o conjunto de sismofácies, contribuindo para evidenciar a forte relação entre as estruturas mostradas em superfície e em subsuperfície (Hampson et al., 2005; Shi and Wang, 2010). A configuração morfológica pretérita auxilia na compreensão dos processos costeiros, favorecendo o conhecimento atual dos ambientes dinâmicos em desenvolvimento (Miall, 2006; Weschenfelder et al., 2010). Para a área de estudo, a identificação de diferentes unidades estruturais e formas de fundo contribuirão para a compreensão dos eventos presentes.

A Unidade I apresenta um arranjo de refletores com terminações paralelas e subparalelas predominante em quase todo o seu domínio. Estas terminações encontram-se normalmente próximas a superfície do fundo inserida a profundidade aproximada de dois metros, entretanto, algumas exceções foram observadas em profundidades superiores a 30 metros abaixo da superfície. Essas exceções provavelmente estão associadas aos eventos de transição de velocidade de fluxo, provocados principalmente por modificações bruscas no regime pluviométrico se avaliarmos em escala regional e/ou pelas mudanças no nível do mar influenciando as condições de descarga em comparação a um quadro global (Packman et al., 2004; Wells, 1990; Zhang et al., 2016). Os refletores nesta unidade apresentam pouca continuidade lateral com contato entre si e perda de reflexão em várias áreas, além de oscilação de amplitude, variando de alta para baixa e vice-versa. Os padrões de reflexão são típicos de ambientes de alta energia com intenso retrabalhamento de sedimentos, favorável a formação de formas de fundo do tipo ripples, em que demonstram elevado grau de modificação em um curto intervalo de tempo (Gomez-Velez et al., 2015; Kuijpers and Nielsen, 2016).

As características e comportamento no arranjo dos refletores na Unidade $I$ configuram a sismofácies do tipo SP2 preenchida por sedimentos de origem fluvial, associados aos ambientes com intenso retrabalhamento e alto poder de transporte de sedimentos (Miall, 1978; Vital et al., 2010). As megaripples são as formas de fundo dominantes na sismofácies do tipo SP2, caracterizando o processo de formação com o desenvolvimento em baixas profundidades e velocidades de corrente elevadas, regulares e predominantemente de vazante (Packman et al., 2004; Pinheiro and Vinzon, 2013). Além do arranjo de terminações foi identificado que as megaripples estão repousadas sobre um refletor de alta amplitude de disposição irregular e perda na continuidade lateral em algumas áreas adjacentes. Este refletor foi denominado de Superfície 1 , a qual está inserida a profundidade média de seis metros com pequenas oscilações dependendo da proximidade do canal. Essas características, geralmente são associadas às superfícies erosivas de depósitos de ambientes fluviais remanescentes da idade do Quaternário (Cooper et al., 2016). 
Barros et al. Caracterização das Principais Feições Superficiais de Fundo e em Subsuperfície no Limite Sudoste da Baía de Macapá, Canal do Norte, Rio Amazonas.

A Unidade $I$ revela o desenvolvimento de sismofácies estratificadas típicas de ambientes dinâmicos com elevado aporte sedimentológico e variação horizontal das feições de fundo (Boyd et al., 1992; Harvey et al., 2005). O ambiente de sedimentação ideal para a formação das megaripples contribui para a configuração do padrão de reflexão característico da sismofácies SP2 identificado no arcabouço sedimentar da Baía de Macapá inserido às menores profundidades, principalmente, de um a seis metros abaixo do substrato (Vital et al., 1998). As exceções identificadas em profundidades superiores a 30 metros podem ser explicadas com a permanência destas formas de leito características de paleofeições, as quais estão associadas e adjacentes a estrutura de paleocanal. Algumas paleofeições mantem as suas características intactas, conservando informações referentes ao ambiente deposicional pretérito como o tipo de transporte, hidrodinâmica, eventos esporádicos cíclicos, etc. (Cartigny et al., 2011; Pigott et al., 2013).

A Unidade II é acusticamente transparente e marcada pela ausência de padrão refletivo com o predomínio de amplitudes variadas, refletores desorganizados e terminações caóticas e assimétricas. Estes refletores encontram-se dispersos, estando presentes em profundidades menores ( 0,5 metros), prolongando-se até profundidades superiores a 40 metros em subsuperfície. Esse comportamento está associado a presença das formas de fundo tipo sand waves presentes em extensos campos, cobrindo alguns pontos do fundo da Baía de Macapá, como o meio e algumas regiões próximas as margens (Stow et al., 2013). Estudos caracterizam as sand waves como feições de baixa penetração do sinal sísmico, devido principalmente pela composição sedimentar e grau de compactação (Adams et al., 1986; Besio et al., 2008). Entretanto, dependendo do método utilizado e logística de levantamento, podem-se obter resultados satisfatórios em relação a investigação em subsuperfície destas formas de fundo (Hampson et al., 2005).

As sand waves normalmente estão associadas a ambientes altamente dinâmicos, sofrendo a ação de fortes correntes unidirecionais como a deriva litorânea típicas em costas desprotegidas ou bidirecionais em ambientes protegidos pela ação das correntes de maré em rios de grande escala, enseadas, baías e lagunas (Baas et al., 2016; Besio et al., 2006). Apesar dos sedimentos arenosos predominantes neste tipo de feição serem rapidamente transportados devido a inconsolidação do substrato, as sand waves configuram um sistema deposicional heterogêneo em relação ao período de formação, onde a modificação temporal dos eventos declina-se aos processos dinâmicos locais (Kuijpers and Nielsen, 2016; Zhang et al., 2016). A permanência de uma forçante atuando de forma contínua durante um longo intervalo de tempo, como a ação das correntes de maré predominantemente de vazante neste trecho da Baía de Macapá, pode ter originado as feições com respectivo arranjo de refletores identificados em subsuperfície (GomezVelez et al., 2015; Gong et al., 2013).

Desta forma, o ambiente de formação dos campos de sand waves proporciona os requisitos adequados para a configuração dos refletores identificados na sismofácies SC (Gomes et al., 
Barros et al. Caracterização das Principais Feições Superficiais de Fundo e em Subsuperfície no Limite Sudoste da Baía de Macapá, Canal do Norte, Rio Amazonas.

2014; Knaapen et al., 2001). Esses refletores geralmente não possuem continuidade lateral, porém, podem apresentar regularidade e padrão de refletividade devido à influência adquirida pelo contato com outras unidades estruturais ou pelo comportamento constante de fluxo havendo poucas alterações em um longo período de atuação (Harvey et al., 2005; Miall, 2006), além de apresentar desconformidades, assimetria e configuração caótica em sua disposição, o qual é comportamento característico de ambientes energéticos com variações abruptas de dinâmica e de forçantes de deformação do processo de sedimentação (Bourgoin et al., 2013; Wittmann et al., 2011), nota-se uma tendência de inclinação de alguns refletores de NW-SE, levando a crer que essas formas de fundo estão se deslocando perpendicularmente a direção do Canal do Norte com transporte de carga de fundo aparente para a montante (Besio et al., 2008; Komarova and Newell, 2000; Strasser, 2008).

A configuração de refletores sotopostos dispostos em plano paralelo caracteriza a Unidade III, classificando esta unidade com um forte padrão refletivo de alinhamento simétrico e elevados valores de amplitude. Os refletores estão inseridos desde as profundidades inferiores próximos a superfície do fundo até profundidades de 30 metros em subsuperfície e possuem grande continuidade lateral estendendo-se por quilômetros de extensão horizontal. Este arranjo de refletores geralmente está relacionado a condições de menor intensidade e constância de fluxo, verificado em locais abrigados em ambientes fluviais como nas proximidades das margens ou ilhas no caso de rios anastomosados, e arredores de feições interferentes da dinâmica natural como sand banks, spits e tidal sand bars (Baas et al., 2016; Neill et al., 2012). A Unidade III associa-se principalmente as margens e as formas de fundo do tipo tidal sand bars predominantes no meio da Baía de Macapá, provavelmente associadas as zonas com as menores velocidades abrigadas pelas ilhas inseridas neste trecho do Canal do Norte (Gallo and Vinzon, 2005).

A diminuição relativa da dinâmica nestas zonas responde a configuração dos refletores em plano paralelo, os quais são associados a ambientes com baixa intensidade de fluxo, retrabalhamento e transporte de sedimento dispersos longitudinalmente (Daniell and Hughes, 2007; Pinheiro and Vinzon, 2013). Embora seja apresentado um elevado grau de horizontalidade nos refletores, percebeu-se a presença de desconformidade em algumas áreas isoladas em aproximadamente dois metros de profundidade abaixo do substrato. Esta característica pode estar relacionada com a variação abrupta no regime de fluxo, onde há anormalidade no processo sedimentológico natural devido a alteração do nível de base, originado a formação de superfícies erosivas (Hampson et al., 2005; Stow et al., 2013). A disposição dos refletores neste arranjo também pode ser verificada nas calhas de canais, onde essa formação é derivada dos extremos valores de velocidade de fluxo (Daniell and Hughes, 2007; Nagata et al., 2000).

Estas características estão presentes na descrição da sismofácies do tipo SP1, a qual é predominante em ambientes de elevada extensão, uniformidade horizontal e processo de sedimentação constante, assim como ambientes típicos de alternâncias litológicas devido ao aporte diversificado de sedimentos com abundância de sedimentos heterogêneos (Jaeger and 
Barros et al. Caracterização das Principais Feições Superficiais de Fundo e em Subsuperfície no Limite Sudoste da Baía de Macapá, Canal do Norte, Rio Amazonas.

Nittrouer, 1995; Wittmann et al., 2011). As exceções identificadas no arranjo interno de reflexão estão associadas a intensa migração das estruturas de fundo localizadas adjacentes as formas tipo tidal sand bars, porém também podem ser identificadas em megaripples, sand waves, canais incisos e até mesmo a migração do canal principal (Besio et al., 2006; Bourgoin et al., 2013). Apesar da divergência de direção de fluxo apresentada nas zonas de mistura nos estuários, os depósitos de limites horizontais são comumente identificados nestes ambientes, associados as zonas de intermaré predominantemente as feições de planícies de maré ou de bancos expostos (Perillo et al., 1993; Pinheiro and Vinzon, 2013).

A Unidade IV apresenta como particularidades, um arranjo de refletores côncavos dispostos espaçadamente em áreas específicas próximas a borda do canal principal e um refletor realçado de fácies progradante inserido abaixo da superfície basal do canal principal localizado a 55 metros. O primeiro arranjo é acompanhado de refletores subparalelos, sobrepostos e mergulhantes em direção ao centro da feição à profundidade em cerca de 50 metros, enquanto que, no segundo arranjo foi observado a presença de refletores paralelos e subparalelos acompanhantes de refletores com terminações superiores e inferiores, tangenciais a superfície basal (superfície de erosão) por volta de 65 metros de profundidade. As elevadas amplitudes presente nos refletores do primeiro e segundo arranjo corroboram a identificação de um embasamento acústico remetendo a feição de paleocalha do antigo canal principal em escala similar ao atual (Cooper et al., 2016; Damuth et al., 1983; Peakall et al., 2007). A identificação dessas feições caracteriza o desenvolvimento de paleofeições, as quais também podem estar associadas as mudanças na configuração neotectônica e alterações abruptas na descarga fluvial com a ação de fenômenos favorecidos pelas condições de maré como o fenômeno da pororoca típico em regiões com a influência de macromaré (Pigott et al., 2013; Santos et al., 2002; Smith et al., 1993).

A unidade também possui alguns canais de incisão medindo em média aproximadamente quatro metros de profundidade, 200 metros de largura e prolongamento na escala de quilômetros. Assim como o predomínio de fácies recumbentes de aproximadamente 15 metros de profundidade próximas as bordas, onde se observou refletores inclinados e côncavos de fácies desconformes, identificação de superfície erosiva e deposição disforme. A ação pretérita de fortes correntes de maré associada as rápidas modificações das condições locais pode ser considera o principal motivo para a alteração do nível de base e consecutivamente para a ação erosiva das feições superficiais (Baas et al., 2016; Kuijpers and Nielsen, 2016). Os canais incisos comparados com os canais principais não apresentam proporções equiparáveis escala, porém equivalem-se no desenvolvimento e atividade dos processos, revelando similaridades na formação das estruturas internas (Vital et al., 2010). As formas de fundo dos tipos canais incisos e canal principal são relacionadas pelo arranjo dos refletores, caracterizados pelas condições e intensidade dos processos locais (Vital et al., 1998). Estas formas de fundo tendem a apresentar elevada taxa de migração horizontal e variação vertical de profundidade, oferecendo condições para o estágio inicial de desenvolvimento de um futuro paleocanal (Camargo et al., 2007; Hooke, 1995), tais 
Barros et al. Caracterização das Principais Feições Superficiais de Fundo e em Subsuperfície no Limite Sudoste da Baía de Macapá, Canal do Norte, Rio Amazonas.

características são consideradas as principais responsáveis pela disposição dos refletores (Gomes et al., 2014; Li et al., 2016).

A análise estrutural demonstra que a Unidade IV é marcada com o predomínio das sismofácies dos tipos SCAN e SS respectivamente, onde se destaca o arranjo sigmoidal, inclinação e terminações tangenciais dos refletores em ambos os casos (Gomes et al., 2014). Este comportamento é típico de ambientes fluviais caracterizados com derivação de meandros proveniente principalmente da variação morfológica de fundo, alteração abrupta no regime de fluxo, controle neotectônico e/ou variabilidade sedimentológica (Damuth et al., 1983; Peakall et al., 2007). Embora as condições de sedimentação sejam diversas em ambientes altamente energéticos, observa-se uma compartimentação da atuação dos processos em decorrência principalmente da própria morfologia do leito (Camargo et al., 2015; Stow et al., 2013). A permanência de uma determinada forma de fundo está associada prioritariamente ao regime de fluxo, profundidade de formação e tipo de sedimento que a compõe (Packman et al., 2004). O padrão de reflexão interna é condicionado ao processo de sedimentação que esta feição sofre e a partir destas características podemos inferir as condições pretéritas do meio (Du et al., 2015; Miall, 2006). Além disso, as diferenças de profundidade, alterações nos padrões de refletividade e modificações no arranjo estrutural interno podem indicar estágios diferentes de sedimentação do canal principal, revelando a importância de testemunhagem na área para a comprovação e validação de tais processos.

\section{CONCLUSÕES}

A região da Baía de Macapá é acometida de constantes alterações geomorfológicas, sendo consolidadas pela ação incessante de processos hidrodinâmicos e sedimentológicos. A consolidação desses processos é determinante para a caracterização, formação e desenvolvimento das estruturas sobre o leito e abaixo do substrato. Logo, pode-se destacar como principais características morfológicas superficiais e subsuperficiais da região da Baía de Macapá:

1. A identificação de cinco principais formas de fundo: Megaripples com a predominância de sedimentos arenosos de granulação fina, localizadas em quase toda a extensão da Baía de Macapá inseridas a profundidade média de 30 metros; Sand Waves formadas praticamente de areia fina a média concentradas em profundidade alternada em zonas próximas aos canais e sobre as formas do tipo Tidal Sand Bars; Tidal Sand Bars formadas com sedimentos arenosos de granulação fina a média e localização restrita as zonas medianas do Canal do Norte e em profundidade em cerca de 10 metros; Canais Incisos localizados estritamente as formas de canais característicos de ambientes altamente energéticos; e Canal Principal ou canais principais identificados em três zonas da Baía de Macapá, sendo margens e meio.

2. A caracterização de quatro unidades estruturais com particularidades em relação ao arcabouço sedimentar: Unidade I - Ripples Cavalgantes; Unidade II - Campos de Sand Waves; Unidade III - Depósitos de Limites Horizontais; e Unidade IV - Canais Incisos Transpostos. Todas 
Barros et al. Caracterização das Principais Feições Superficiais de Fundo e em Subsuperfície no Limite Sudoste da Baía de Macapá, Canal do Norte, Rio Amazonas.

as unidades apresentam configuração estrutural e deposicional de sequencias em estratos, caracterizando sismofácies de ambientes de elevada energia.

3. A classificação de cinco sismofácies de acordo com os padrões de reflexão interna, arranjo estrutural, formas de preenchimento, amplitude e continuidade lateral dos refletores: Sismofácies tipo SP1 caracterizadas pelo arranjo plano paralelo de refletores acamados, elevada continuidade lateral e zonas de desconformidade, sendo associadas principalmente as formas de fundo do tipo Tidal Sand Bars; Sismofácies tipo SP2, as quais apresentam refletores de alta amplitude paralelos e subparalelos e baixa continuidade lateral, identificada normalmente junto com as formas de fundo tipo Megaripples; Sismofácies tipo SC caracterizada pela camada de transparência acústica com exceção de alguns refletores inclinados e desorganizados identificados abaixo dos campos de Sand Waves; Sismofácies tipo SS e Sismofácies tipo SCAN, ambas associadas a forma de fundo do tipo canal com a demonstração de refletores inclinados e recumbentes de assinatura tangencial e sigmoide com a presença de fácies progradantes.

4. As variações morfológicas das formas de fundo, gerando subsídios e embasamento científico para a compreensão complexa da configuração de reflexão interna e disposição de acomodação dos sedimentos em subsuperfície.

5. A identificação de dois refletores de alta amplitude inseridos ao Canal Principal da margem esquerda de Macapá/Fazendinha a aproximadamente 55 e 65 metros em subsuperfície, levantando o indício de uma feição de paleocanal, havendo a possibilidade da ocorrência de eventos de sedimentação em períodos distintos.

\section{AGRADECIMENTOS}

Agradeço ao Projeto AMAZ por subsidiar e fornecer a logística necessária. Aos integrantes e colaboradores no levantamento dos dados, apoio e logística. Aos professores incentivadores desta pesquisa, em agradecimento especial a Profa. Dra. Odete Silveira (in memoriam) por compartilhar seu pensamento entusiasta ao avanço da pesquisa na Região Norte do Brasil.

\section{REFERÊNCIAS BIBLIOGRÁFICAS}

Adams, C.E., Wells, J.T. and Coleman, J.M. (1986), Transverse bedforms on the Amazon shelf, Continental Shelf Research, Vol. 6, No. 1-2, pp. 175-187.

AmasSeds, G.R. (1990), A multidisciplinary Amazon shelf sediment study, EOS Transactions, Vol. 71, pp. 1771-1777.

Baas, J.H., Best, J.L. and Peakall, J. (2016), Predicting bedforms and primary current stratification in cohesive mixtures of mud and sand, Journal of the Geological Society, Vol. 173, No. 1, pp. $12-45$.

Besio, G., Blondeaux, P. and Vittori, G. (2006), On the formation of sand waves and sand banks, Journal of Fluid Mechanics, Vol. 557, No. 1, pp. 1-27. 
Barros et al. Caracterização das Principais Feições Superficiais de Fundo e em Subsuperfície no Limite Sudoste da Baía de Macapá, Canal do Norte, Rio Amazonas.

Besio, G., Blondeaux, P., Van Lancker, V., Verfaillie, E. and Vittori, G. (2008), Sand waves characteristics: Theoretical predictions versus field data, River, Coastal and Estuarine Morphodynamics, RCEM 2007, Vols 1 and 2, pp. 985-992.

Bourgoin, L.M., Bonnet, M.P., Martinez, J.-M.M., Kosuth, P., Cochonneau, G., Moreira-Turcq, P. and Seyler, P. (2013), Temporal dynamics of water and sediment exchanges between the Curuaí floodplain and the Amazon River, Brazil, Journal of Hydrology, Vol. 335, No. 1-2, pp. 140-156.

Boyd, R., Dalrymple, R. and Zaitlin, B.A. (1992), Classification of clastic coastal depositional environments, Sedimentary Geology, Vol. 80, No. 3-4, pp. 139-150.

Camargo, J.M.R., Araújo, T.C.M., Maida, M. and Ushizima, T.M. (2007), Morfologia da Plataforma Continental Interna Adjacente ao Município de Tamandaré, Pernambuco, Brasil, Revista Brasileira de Geofísica, Vol. 25, Supl. 1, pp. 79-89.

Camargo, J.M.R., Araújo, T.C.M., Ferreira, B.P. and Maida, M. (2015), Topographic features related to recent sea level history in a sediment-starved tropical shelf: Linking the past, present and future, Regional Studies in Marine Science, Vol. 2, pp. 203-211.

Cartigny, M.J.B., Postma, G., van den Berg, J.H. and Mastbergen, D.R. (2011), A comparative study of sediment waves and cyclic steps based on geometries, internal structures and numerical modeling, Marine Geology, Vol. 280, No. 1, pp. 40-56.

Constantine, J.A., Dunne, T., Ahmed, J., Legleiter, C. and Eli, D. (2014), Sediment supply as a driver of river evolution in the Amazon Basin, Nature Geoscience, Vol. 7, pp. 899-903.

Cooper, J.A.G., Green, A.N., Meireles, R.P., Klein, A.H.F., Souza, J. and Toldo Jr., E E. (2016), Sandy barrier overstepping and preservation linked to rapid sea level rise and geological setting, Marine Geology, Vol. 382, pp. 80-91.

Dalrymple, R.W., Zaitlin, B.A. and Boyd, R. (1992), Estuarine facies models - conceptual basis and stratigraphic implications, Journal of Sedimentary Research, Vol. 62, No. 6, pp. 11301146.

Damuth, J.E., Kolla, V., Flood, R.D., Kowsmann, R.O., Monteiro, M.C., Gorini, M.A., Palma, J.J.C. and Belderson, R.H. (1983), Distributary channel meandering and bifurcation patterns on the Amazon deep-sea fan as revealed by long-range side-scan sonar (GLORIA), Geology, Vol. 11, No. 2, pp. 94-98.

Daniell, J.J. and Hughes, M. (2007), The morphology of barchan-shaped sand banks from western Torres Strait, northern Australia, Sedimentary Geology, Vol. 202, No. 4, pp. 638-652.

Du, H., Cao, J., Xue, Y. and Wang, X. (2015), Seismic facies analysis based on self-organizing map and empirical mode decomposition, Journal of Applied Geophysics, Vol. 112, pp. 5261.

Dunne, T., Mertes, L.A.K., Meade, R.H., Richey, J.E. and Forsberg, B.R. (1998), Exchanges of sediment between the flood plain and channel of the Amazon River in Brazil, Bulletin of the Geological Society of America, Vol. 110, No. 4, pp. 450-467. 
Barros et al. Caracterização das Principais Feições Superficiais de Fundo e em Subsuperfície no Limite Sudoste da Baía de Macapá, Canal do Norte, Rio Amazonas.

Fernandes, R.D., Vinzon, S.B. and Oliveira, F.A.M. (2007), Navigation at the Amazon River Mouth: Sand Bank Migration and Depth Surveying, 11th Triennial International Conference on Ports, pp. $1-10$.

Gallo, M.N. and Vinzon, S.B. (2005), Generation of overtides and compound tides in Amazon estuary, Ocean Dynamics, Vol. 55, No. 5-6, pp. 441-448.

Geyer, W.R., Hill, P.S. and Kineke, G.C. (2004), The transport, transformation and dispersal of sediment by buoyant coastal flows, Continental Shelf Research, Vol. 24, No. 7, pp. 927949.

Gomes, M.P., Vital, H., Bezerra, F.H.R., de Castro, D.L. and Macedo, J.W. de P. (2014), The interplay between structural inheritance and morphology in the Equatorial Continental Shelf of Brazil, Marine Geology, Vol. 355, pp. 150-161.

Gomez-Velez, J.D., Harvey, J.W., Cardenas, M.B., and Kiel, B. (2015), Denitrification in the Mississippi River network controlled by flow through river bedforms, Nature Geoscience, Vol. 8, pp. $1-8$.

Gong, C., Wang, Y., Zhu, W., Li, W., and Xu, Q. (2013), Upper Miocene to Quaternary unidirectionally migrating deep-water channels in the Pearl River Mouth Basin, northern South China Sea, AAPG Bulletin, Vol. 97, No. 2, pp. 285-308.

Guennec, B. Le and Strasser, M.A. (2007), O Transporte de Sedimentos em Suspensão no Rio Amazonas - O papel do leito médio e maior na avaliação da capacidade de transporte dos sedimentos finos em regime não permanente, XVII Simpósio Brasileiro de Recursos Hídricos, pp. 1-14.

Hampson, G.J., Davies, W., Davies, S.J., Howell, J.A. and Adamson, K.R. (2005), Use of spectral gamma-ray data to refine subsurface fluvial stratigraphy: late Cretaceous strata in the Book Cliffs, Utah, USA, Journal of Geological Society, Vol. 162, pp. 603-621.

Harvey, A.M., Mather, A.E. and Stokes, M. (2005), Alluvial fans: geomorphology, sedimentology, dynamics - introduction, A review of alluvial-fan research, in Harvey, A.M., Mather, A.E. and Stokes, M. (Eds), Alluvial fans: Geomorphology, Sedimentology, Dynamics, Geological Society, London, Special Publications, Vol. 251, No. 1, pp. 1-7.

Hooke, J.M. (1995), River channel adjustment to meander cutoffs on the River Bollin and River Dane, northwest England, Geomorphology, Vol. 14, No. 3, pp. 235-253.

Jaeger, J.M. and Nittrouer, C.A. (1995), Tidal controls on the formation of fine-scale sedimentary strata near the Amazon river mouth, Marine Geology, Vol. 125, No. 3-4, pp. 259-281.

Knaapen, M.A.F., Hulscher, S.J.M.H., De Vriend, H.J. and Stolk, A. (2001), A new type of sea bed waves, Geophysical Research Letters, Vol. 28, No. 7, pp. 1323-1326.

Komarova, N.L. and Newell, A.C. (2000), Nonlinear dynamics of sandbanks and sand waves, Journal of Fluid Mechanics, Vol. 415, pp. 285-321. 
Barros et al. Caracterização das Principais Feições Superficiais de Fundo e em Subsuperfície no Limite Sudoste da Baía de Macapá, Canal do Norte, Rio Amazonas.

Kuijpers, A. and Nielsen, T. (2016), Near-bottom current speed maxima in North Atlantic contourite environments inferred from current-induced bedforms and other seabed evidence, Marine Geology, Vol. 378, pp. 230-236.

Li, X.S., Zhao, Y.X., Feng, Z.B., Liu, C.G., Xie, Q.H. and Zhou, Q.J. (2016), Quaternary seismic facies of the South Yellow Sea shelf: depositional processes influenced by sea-level change and tectonic controls, Geological Journal, Vol. 51, pp. 77-95.

Marroquín, I.D. (2014), Special section : Seismic attributes - A knowledge-integration framework for interpreting seismic facies, Society of Exploration Geophysicists, Vol. 2, No. 1, pp. 1-9.

Martinez, J.M., Guyot, J.L., Filizola, N. and Sondag, F. (2009), Increase in suspended sediment discharge of the Amazon River assessed by monitoring network and satellite data, Catena, Vol. 79, No. 3, pp. 257-264.

Miall, A.D. (1978), Lithofacies types and vertical profile models in braided river deposits: a summary, Fluvial Sedimentology, Vol. 5, pp. 597-600.

Miall, A.D. (2002), Architecture and sequence stratigraphy of Pleistocene fluvial systems in the Malay Basin, based on seismic time-slice analysis, AAPG Bulletin, Vol. 86, No. 7, pp. 12011216.

Miall, A.D. (2006), Reconstructing the architecture and sequence stratigraphy of the preserved fluvial record as a tool for reservoir development: A reality check, AAPG Bulletin, Vol. 90, No. 7, pp. 989-1002.

Mitchum Jr, R.M., Vail, P.R. and Sangree, J.B. (1977), Stratigraphic interpretation of seismic reflection patterns in depositional sequences: Section 2, Application of seismic reflection configuration to stratigraphic interpretation, in Seismic Stratigraphy-Applications to Hydrocarbon Exploration, AAPG Special Volumes, pp. 117-133.

Molion, L. (1987), Climatologia Dinâmica da região Amazônica: mecanismos de precipitação. Revista Brasileira de Meteorologia, Vol. 2, pp. 107-117.

Nagata, N., Hosoda, T. and Muramoto, Y. (2000), Numerical analysis of river channel process with bank erosion, Journal of Hydraulic Engineering, Vol. 126, No. 4, pp. 243-252.

Neill, S.P., Jordan, J.R. and Couch, S.J. (2012), Impact of tidal energy converter (TEC) arrays on the dynamics of headland sand banks, Renewable Energy, Vol. 37, No. 1, pp. 387-397.

Packman, A.I., Salehin, M. and Zaramella, M. (2004), Hyporheic Exchange with Gravel Beds: Basic Hydrodynamic Interactions and Bedform-Induced Advective Flows, Journal of Hydraulic Engineering, Vol. 130, No. 7, pp. 647-656.

Park, E. and Latrubesse, E.M. (2014), Modeling suspended sediment distribution patterns of the Amazon River using MODIS data, Remote Sensing of Environment, Vol. 147, pp. 232-242.

Peakall, J., Amos, K.J., Keevil, G.M., Bradbury, P.W. and Gupta, S. (2007), Flow processes and sedimentation in submarine channel bends, Marine and Petroleum Geology, Vol. 24, No. 69, pp. 470-486. 
Barros et al. Caracterização das Principais Feições Superficiais de Fundo e em Subsuperfície no Limite Sudoste da Baía de Macapá, Canal do Norte, Rio Amazonas.

Perillo, G.M.E., Drapeau, G., Piccolo, M.C. and Chaouq, N. (1993), Tidal circulation pattern on a tidal flat, Minas Basin, Canada, Marine Geology, Vol. 112, No. 1-4, pp. 219-236.

Pigott, J.D., Kang, M.H., and Han, H.C. (2013), First order seismic attributes for clastic seismic facies interpretation: Examples from the East China Sea, Journal of Asian Earth Sciences, Vol. 66, pp. 34-54.

Pinheiro, F.M. and Vinzon, S.B. (2013), Seabed features characterization of Barra Norte by multibeam survey: Furrows evidence at the outermost river branch of the Amazon River. In Acoustics in Underwater Geosciences Symposium (RIO Acoustics), IEEE/OES, pp. 1-7.

Ribeiro, H.J.P.S. (2001), Estratigrafia de sequências: fundamentos e aplicações, São Leopoldo, UNISINOS, 428p.

Santos, V.F., Figueiredo Jr, A.G., Silveira, O.F.M. and Polidori, L. (2002), Mecanismos de Modificações de Curto Período na Planície Costeira do Amapá, in IV ABEQUA, Recife-PE, CDROM, Vol. 9, p. 5.

Santos, V.F., Figuereido Jr., A.G., Silveira, O.F.M., Polidori, L., Oliveira, D.M., Dias, M.B., Martins, M.H. de A. and Santana, L. de O. (2005), Processos Sedimentares em Área de Macro-Marés Influenciados pela Pororoca-Estuário do Rio Araguari-Amapá-Brasil, in $X$ ABEQUA, Guarapari-ES, CD-ROM, p. 6.

Santos, V.F., Polidori, L., da Silveira, O.F.M. and de Figueiredo, A.G. (2009), Aplicação de dados multisensor (SAR e ETM+) no reconhecimento de padrões de uso e ocupação do solo em costas tropicais: Costa Amazônica, Amapá, Brasil, Revista Brasileira de Geofísica, Vol. 27, Suppl. 1, pp. 39-55.

Shi, W. and Wang, M. (2010), Satellite observations of the seasonal sediment plume in central East China Sea, Journal of Marine Systems, Vol. 82, No. 4, pp. 280-285.

Smith, R.M.H., Mason, T.R. and Ward, J.D. (1993), Flash-flood sediments and ichnofacies of the Late Pleistocene Homeb Silts, Kuiseb River, Namibia, Sedimentary Geology, Vol. 85, No. 14, pp. 579-599.

Stow, D.A.V, Hernández-Molina, F.J., Llave, E., Bruno, M., García, M., Díaz del Rio, V., Brackenridge, R.E. (2013), The Cadiz Contourite Channel: Sandy contourites, bedforms and dynamic current interaction, Marine Geology, Vol. 343, pp. 99-114.

Strasser, M.A. (2002), Estudo Da Geometria Das Formas De Fundo No Curso Médio Do Rio Amazonas, Dissertação de Mestrado, Universidade Federal do Rio de Janeiro, 100p.

Strasser, M.A. (2008), Dunas Fluviais No Rio Solimões-Amazonas - Dinâmica E Transporte De Sedimentos, Tese de Doutorado, Universidade Federal do Rio de Janeiro, 148p.

Strasser, M.A., Vinzon, S. and Kosuth, P. (2002), Bottom structures geometry of the Amazon River, In Proceedings of the International Conference on Fluvial Hydraulics, Louvain-LaNeuve, Belgium, pp. 4-6.

Torres, A.M. (1997), Sedimentology of the Amazon mouth: north and south channels, Brazil, Geologisch-Paläontologisches Institut und Museum, Christian-Albrechts-Universität. 
Barros et al. Caracterização das Principais Feições Superficiais de Fundo e em Subsuperfície no Limite Sudoste da Baía de Macapá, Canal do Norte, Rio Amazonas.

Vilela, C. de P.X. (2011), Influência da Hidrodinâmica Sobre os Processos de Acumulação de Sedimentos Finos no Estuário do Rio Amazonas, Tese de Doutorado, Universidade Federal do Rio de Janeiro, 85p.

Vinzon, S., Gallo, M., Fernandes, R.D. and Silva, I. (2005), A Characterization of the Amazon Estuary, from Obidos to the Continental Shelf, in $X A B E Q U A$, Guarapari-ES, CD-ROM, pp. $1-3$.

Vital, H., Stattegger, K., Posewang, J. and Theilen, F. (1998), Lowermost Amazon River: Morphology and shallow seismic characteristics, Marine Geology, Vol. 152, No. 4, pp. 277294.

Vital, H. and Stattegger, K. (2000a), Lowermost Amazon River: Evidence of late Quaternary sealevel fluctuations in a complex hydrodynamic system, Quaternary International, Vol. 72, pp. 53-60.

Vital, H. and Stattegger, K. (2000b), Major and trace elements of stream sediments from the lowermost Amazon River. Chemical Geology, Vol. 168, No. 1, pp. 151-168.

Vital, H., Furtado, S.F.L. and Gomes, M.P. (2010), Response of the Apodi-Mossoró Estuary-Incised Valley System (NE Brazil) to Sea-Level Fluctuations, Brazilian Journal of Oceanography, Vol. 58, Special Issue 2, pp. 13-24.

Wells, L.E. (1990), Holocene history of the El Nino phenomenon as recorded in flood sediments of northern coastal Peru, Geology, Vol. 18, No. 11, pp. 1134-1137.

Weschenfelder, J., Corrêa, I.C.S., Toldo Jr, E.E., and Baitelli, R. (2010), A drenagem pretérita do Rio Camaquã na costa do Rio Grande do Sul, Pesquisas em Geociências, Vol. 37, No. 1, pp. 13-23.

Wittmann, H., von Blanckenburg, F., Maurice, L., Guyot, J.L., Filizola, N. and Kubik, P.W. (2011), Sediment production and delivery in the Amazon River basin quantified by in situ-produced cosmogenic nuclides and recent river loads, Bulletin of the Geological Society of America, Vol. 123, No. 5, pp. 934-950.

Zhang, Y., Lu, X., Shao, X., Chen, C., Li, X., Zhao, F., Lig, G. and Matsumoto, E. (2016), Temporal variation of sedimentation rates and potential factors influencing those rates over the last 100 years in Bohai Bay, China, Science of the Total Environment, Vol. 572, pp. 68-76. 